\title{
The Highly Deuterated Chemistry of the Early Universe
}

\section{Citation}

Gay, C. D., P. C. Stancil, S. Lepp, and A. Dalgarno. 2011. “The Highly Deuterated Chemistry of the Early Universe." The Astrophysical Journal 737 (1) (August 10): 44.

\section{Published Version}

doi:10.1088/0004-637X/737/1/44

\section{Permanent link}

http://nrs.harvard.edu/urn-3:HUL.InstRepos:12718785

\section{Terms of Use}

This article was downloaded from Harvard University's DASH repository, and is made available under the terms and conditions applicable to Other Posted Material, as set forth at http:// nrs.harvard.edu/urn-3:HUL.InstRepos:dash.current.terms-of-use\#LAA

\section{Share Your Story}

The Harvard community has made this article openly available.

Please share how this access benefits you. Submit a story.

Accessibility 


\title{
THE HIGHLY DEUTERATED CHEMISTRY OF THE EARLY UNIVERSE
}

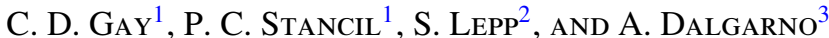 \\ ${ }^{1}$ Department of Physics and Astronomy and Center for Simulational Physics, The University of Georgia, \\ Athens, GA 30602-2451, USA; cgay1383@gmail.com, stancil@physast.uga.edu \\ 2 Department of Physics, University of Nevada, Las Vegas, NV 89154-4002, USA; lepp@ unlv.nevada.edu \\ ${ }^{3}$ Harvard-Smithsonian Center for Astrophysics, Cambridge, MA 02138, USA; adalgarno@ cfa.harvard.edu \\ Received 2010 September 27; accepted 2011 June 2; published 2011 July 27
}

\begin{abstract}
A comprehensive chemistry of the highly deuterated species $\mathrm{D}_{2}, \mathrm{D}_{2}^{+}, \mathrm{D}_{2} \mathrm{H}^{+}$, and $\mathrm{D}_{3}^{+}$in the early universe is presented. Fractional abundances for each are calculated as a function of redshift $z$ in the recombination era. The abundances of the isotopologues are found to display similar behavior. Fractionation enhances the abundances of most of the more highly deuterated species as the redshift decreases due to the closing of some reaction channels as the gas temperature cools. Rate coefficients for the majority of the reactions involving the deuterated species are uncertain resulting in a corresponding uncertainty in their predicted abundances.
\end{abstract}

Key words: early universe - molecular data - molecular processes - nuclear reactions, nucleosynthesis, abundances

Online-only material: machine-readable table

\section{INTRODUCTION}

Chemistry networks for the early universe have been developed by Black (1981), Galli \& Palla (1998), Stancil et al. (1998), Lepp et al. (2002), Glover \& Abel (2008), and others. These networks incorporated primordial atoms, ions, and molecules, often including deuterated species. However, highly deuterated species, those containing more than a single deuterium atom, were neglected in all but Glover \& Abel (2008), who considered $\mathrm{D}_{2}$ and $\mathrm{D}_{2}^{+}$.

Here we expand upon the network developed by Stancil et al. (1998) and Lepp et al. (2002) by adding a comprehensive set of reactions for $\mathrm{D}_{2}, \mathrm{D}_{2}^{+}, \mathrm{D}_{2} \mathrm{H}^{+}$, and $\mathrm{D}_{3}^{+} . \mathrm{D}_{2} \mathrm{H}^{+}$was detected in the prestellar core $16293 \mathrm{E}$ by Vastel et al. (2004) who emphasized its importance, as well as that of $\mathrm{D}_{3}^{+}$, in determining the total deuterium abundance in the gas phase. These highly deuterated species are likely formed in the early universe. $\mathrm{D}_{2} \mathrm{H}^{+}$possesses a dipole moment $(\sim 0.5 \mathrm{D})$. Therefore, if it is present in sufficient quantities, it may be observable. Furthermore, the current chemical model includes updated cosmological parameters.

In the next section, we outline the important reactions relevant to the formation and destruction of the highly deuterated species. Section 3 discusses the adopted rate coefficients, while simulations of chemistry in the early universe are presented in Section 4. We conclude in Section 5 with a call for further studies into deuterium reactions.

\section{EARLY UNIVERSE CHEMISTRY}

The network of Stancil et al. (1998) and Lepp et al. (2002) contained 146 reactions. With the introduction of $\mathrm{D}_{2}, \mathrm{D}_{2}^{+}, \mathrm{D}_{2} \mathrm{H}^{+}$, and $\mathrm{D}_{3}^{+}$to the network, this total is brought to 256 . The complete network is given in Table 1 . Here we indicate those reactions subsequently found to be the most important for determining the abundances of the highly deuterated species.

$\mathrm{D}_{2}$ is primarily created through the exchange reactions,

$$
\mathrm{D}^{+}+\mathrm{HD} \rightarrow \mathrm{H}^{+}+\mathrm{D}_{2}
$$

and

$$
\mathrm{HD}+\mathrm{D} \rightarrow \mathrm{D}_{2}+\mathrm{H}
$$

while being destroyed most efficiently by the reverse processes,

$$
\mathrm{H}^{+}+\mathrm{D}_{2} \rightarrow \mathrm{D}^{+}+\mathrm{HD}
$$

and

$$
\mathrm{D}_{2}+\mathrm{H} \rightarrow \mathrm{HD}+\mathrm{D},
$$

and the deuterium abstraction reaction,

$$
\mathrm{H}_{2}^{+}+\mathrm{D}_{2} \rightarrow \mathrm{H}_{2} \mathrm{D}^{+}+\mathrm{D} .
$$

$\mathrm{D}_{2}^{+}$is primarily created through radiative association,

$$
\mathrm{D}+\mathrm{D}^{+} \rightarrow \mathrm{D}_{2}^{+}+h v
$$

ion-ion associative attachment,

$$
\mathrm{D}^{+}+\mathrm{D}^{-} \rightarrow \mathrm{D}_{2}^{+}+e^{-}
$$

and the exchange reactions,

$$
\mathrm{HeD}^{+}+\mathrm{D} \rightarrow \mathrm{D}_{2}^{+}+\mathrm{He}
$$

and

$$
\mathrm{HD}^{+}+\mathrm{D} \rightarrow \mathrm{D}_{2}^{+}+\mathrm{H} .
$$

It is predominantly destroyed by photodissociation due to the cosmic background radiation field,

$$
\mathrm{D}_{2}^{+}+h v \rightarrow \mathrm{D}+\mathrm{D}^{+},
$$

dissociative recombination,

$$
\mathrm{D}_{2}^{+}+e^{-} \rightarrow \mathrm{D}+\mathrm{D},
$$

charge transfer,

$$
\mathrm{D}_{2}^{+}+\mathrm{H} \rightarrow \mathrm{D}_{2}+\mathrm{H}^{+},
$$

and the exchange reactions,

$$
\mathrm{D}_{2}^{+}+\mathrm{H} \rightarrow \mathrm{HD}+\mathrm{D}^{+}
$$

and

$$
\mathrm{D}_{2}^{+}+\mathrm{H} \rightarrow \mathrm{HD}^{+}+\mathrm{D} .
$$


$\mathrm{D}_{2} \mathrm{H}^{+}$is primarily created through radiative association,

$$
\begin{gathered}
\mathrm{HD}+\mathrm{D}^{+} \rightarrow \mathrm{D}_{2} \mathrm{H}^{+}+h v, \\
\mathrm{HD}^{+}+\mathrm{D} \rightarrow \mathrm{D}_{2} \mathrm{H}^{+}+h v, \\
\mathrm{D}_{2}^{+}+\mathrm{H} \rightarrow \mathrm{D}_{2} \mathrm{H}^{+}+h v,
\end{gathered}
$$

and

$$
\mathrm{D}_{2}+\mathrm{H}^{+} \rightarrow \mathrm{D}_{2} \mathrm{H}^{+}+h v
$$

as well as exchange,

$$
\begin{gathered}
\mathrm{H}_{2}^{+}+\mathrm{D}_{2} \rightarrow \mathrm{D}_{2} \mathrm{H}^{+}+\mathrm{H}, \\
\mathrm{HD}^{+}+\mathrm{HD} \rightarrow \mathrm{D}_{2} \mathrm{H}^{+}+\mathrm{H},
\end{gathered}
$$

and

$$
\mathrm{H}_{2} \mathrm{D}^{+}+\mathrm{D} \rightarrow \mathrm{D}_{2} \mathrm{H}^{+}+\mathrm{H},
$$

while the predominant destruction reactions are dissociative recombination,

$$
\begin{aligned}
& \mathrm{D}_{2} \mathrm{H}^{+}+e^{-} \rightarrow \mathrm{D}_{2}+\mathrm{H}, \\
& \mathrm{D}_{2} \mathrm{H}^{+}+e^{-} \rightarrow \mathrm{HD}+\mathrm{D},
\end{aligned}
$$

and

$$
\mathrm{D}_{2} \mathrm{H}^{+}+e^{-} \rightarrow \mathrm{H}+\mathrm{D}+\mathrm{D},
$$

and deuterium-hydrogen exchange,

$$
\mathrm{D}_{2} \mathrm{H}^{+}+\mathrm{H} \rightarrow \mathrm{H}_{2} \mathrm{D}^{+}+\mathrm{D} \text {. }
$$

Finally, $\mathrm{D}_{3}^{+}$is mostly created by radiative association,

$$
\mathrm{D}_{2}+\mathrm{D}^{+} \rightarrow \mathrm{D}_{3}^{+}+h v
$$

and

$$
\mathrm{D}_{2}^{+}+\mathrm{D} \rightarrow \mathrm{D}_{3}^{+}+h v
$$

and exchange,

$$
\mathrm{D}_{2} \mathrm{H}^{+}+\mathrm{D} \rightarrow \mathrm{D}_{3}^{+}+\mathrm{H},
$$

while being primarily destroyed by dissociative recombination,

$$
\mathrm{D}_{3}^{+}+e^{-} \rightarrow \mathrm{D}_{2}+\mathrm{D}
$$

and

$$
\mathrm{D}_{3}^{+}+e^{-} \rightarrow \mathrm{D}+\mathrm{D}+\mathrm{D}
$$

\begin{tabular}{|c|c|c|c|c|c|c|c|}
\hline Index & Reactants & & Products & & $a_{1}\left(\mathrm{~cm}^{3} \mathrm{~s}^{-1}\right)$ & $a_{2}$ & $a_{3}(\mathrm{~K})$ \\
\hline 1 & $\mathrm{H}^{+}$ & $e$ & $\mathrm{H}$ & Photon & $3.60-12$ & $-7.50-1$ & 0.0 \\
\hline 2 & $\mathrm{H}$ & Photon & $\mathrm{H}^{+}$ & $e$ & $1.14+7$ & 9.8-1 & $1.57+5$ \\
\hline 3 & $\mathrm{H}$ & $e$ & $\mathrm{H}^{-}$ & Photon & $3.00-16$ & $9.5-1$ & $9.32+3^{\mathrm{a}}$ \\
\hline
\end{tabular}

and exchange,

$$
\mathrm{D}_{3}^{+}+\mathrm{H} \rightarrow \mathrm{D}_{2} \mathrm{H}^{+}+\mathrm{D} \text {. }
$$

These reactions and their rate equations produce a stiff set of coupled differential equations for the densities $n(x)$ of the species of the form

$$
\begin{aligned}
d n(x) / d t= & \alpha_{\text {form }}\left(T_{\mathrm{m}}\right) n(y) n(w)-\alpha_{\text {dest }}\left(T_{\mathrm{m}}\right) n(x) n(u) \\
& -\zeta_{\text {dest }}\left(T_{\mathrm{r}}\right) n(x)+\cdots
\end{aligned}
$$

where the rate coefficients for formation $\alpha_{\text {form }}$ and destruction $\alpha_{\text {dest }}$ depend on the matter temperature $T_{\mathrm{m}}$, the photodestruction rates $\zeta_{\text {dest }}$ depend on the radiation temperature $T_{\mathrm{r}}$, and the set is integrated over time.
Table 1

Reaction Rate Coefficients

Notes. ${ }^{\text {a }}$ Reaction uses the endoergic form.

(This table is available in its entirety in a machine-readable form in the online journal. A portion is shown here for guidance regarding its form and content.)

In the recombination epoch, the hydrogen density is given as

$$
n_{\mathrm{H}}=1.123 \times 10^{-5}\left(1-Y_{p}\right) \Omega_{\mathrm{b}} h^{2}(1+z)^{3} \mathrm{~cm}^{-3},
$$

where $\Omega_{\mathrm{b}}$ is the ratio of the baryonic matter density to the critical density, $h$ is the Hubble constant (in units of $100 \mathrm{~km} \mathrm{~s}^{-1} \mathrm{Mpc}^{-1}$ ), $Y_{p}$ is the helium mass fraction, and $z$ is the redshift. $z$ is related to time by

$$
d t / d z=\left(3.086 \times 10^{17}\right) /\left(h(1+z)^{2}\left(1+\Omega_{\mathrm{m}} z\right)^{1 / 2}\right) \mathrm{s}^{-1}
$$

(e.g., Peebles 1993).

$\Omega_{0}$ is taken to be 1.005 for closure, while we adopted $\Omega_{\mathrm{b}}=0.0456, h=H_{0} / 100=0.705$ (Hinshaw et al. 2009), and the total matter density ratio $\Omega_{\mathrm{m}}=0.33$. For the elemental abundances, we adopted $Y_{p}=0.248$ (Porter et al. 2009), $n_{\mathrm{D}} / n_{\mathrm{H}}=2.550 \times 10^{-5}$, and $n_{\mathrm{Li}} / n_{\mathrm{H}}=5.031 \times 10^{-10}$ (Burles et al. 2001), where $\eta_{10}=6.209$ (Hinshaw et al. 2009) was used.

\section{RATE COEFFICIENTS}

We have obtained reaction rate coefficients by three methods: (1) direct adoption from the literature, (2) calculation from available cross sections, or (3) assumption of simple mass scaling from related reactions of different isotopologues. All rate coefficients were fit to the form

$$
\alpha=a_{1}(T / 300)^{a_{2}} \exp \left(-a_{3} / T\right)
$$

for endoergic reactions and

$$
\alpha=a_{1}(T / 300)^{a_{2}} \exp \left(-T / a_{3}\right)
$$

for exoergic reactions where the data are sufficient to describe the temperature dependence. Simple mass scaling was accomplished by the approximate relation

$$
a_{1, \text { new }}=a_{1, \mathrm{p}}\left(\mu_{\mathrm{p}} / \mu_{\text {new }}\right)^{a_{2, \mathrm{p}}+0.5},
$$

where $a_{1, \mathrm{p}}$ and $a_{2, \mathrm{p}}$ are from the parent reaction, $a_{1, \text { new }}$ is for the new reaction, and $\mu_{\mathrm{p}}$ and $\mu_{\text {new }}$ are the reduced masses of the reactants of the parent and new reactions, respectively. If $a_{2, \mathrm{p}}>-0.5$, the magnitude of the rate coefficient decreases when $\mu_{\text {new }}>\mu_{\mathrm{p}}$.

Henceforth, reaction numbers refer to the numbering in Table 1, while numbers in parentheses correspond to the numbering in Equations (1)- (31). Rate coefficients for reactions 147, 148 (1), 149-151, 153 (3), and 154 in Table 1 were obtained from cross sections in Wang \& Stancil (2002). Similarly, rate coefficients for reactions $155-158$ in our table were obtained from cross sections in Linder et al. (1995). We calculated rate coefficients from their cross sections and fit them to the same forms for $\alpha$ as above. All other rate coefficients were 

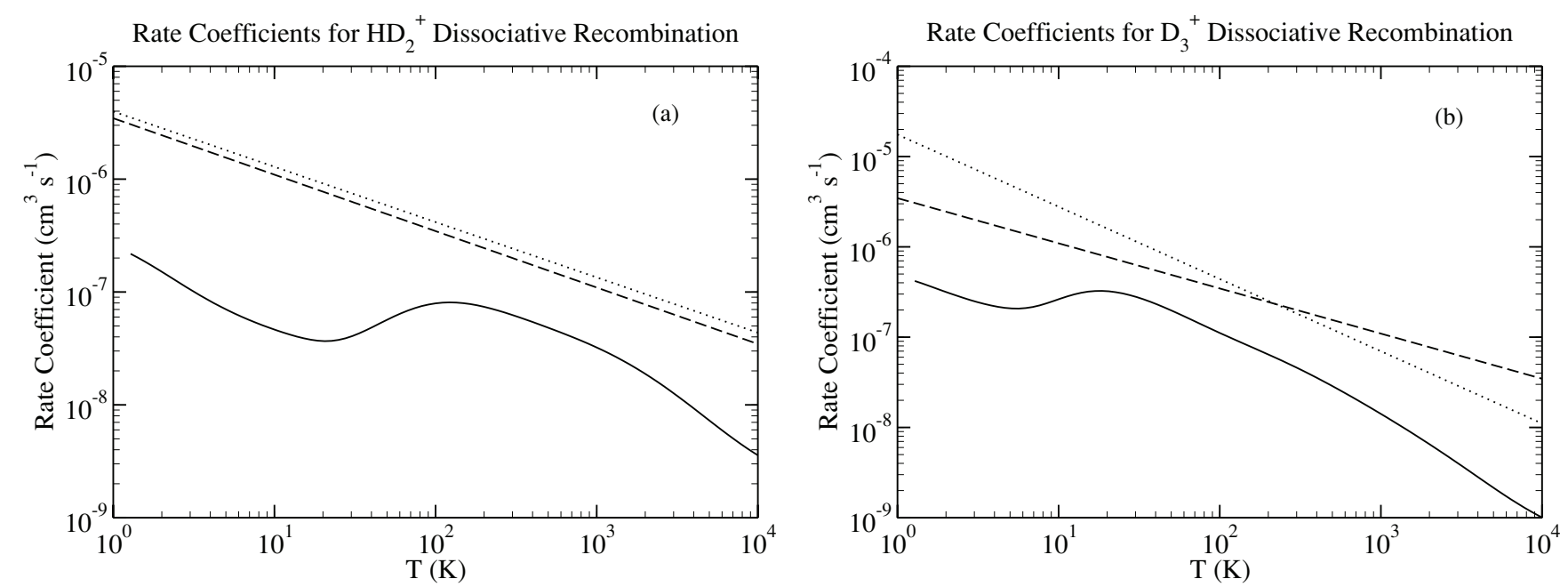

Figure 1. Total rate coefficients for dissociative recombination for (a) $\mathrm{D}_{2} \mathrm{H}^{+}(22-24)$ and (b) $\mathrm{D}_{3}^{+}(29,30)$. Solid line: (a) Kokoouline \& Greene (2005) and (b) Kokoouline \& Greene (2003), dotted line: Mitchell et al. (1984), and dashed line: scaled from Wolf et al. (2006).

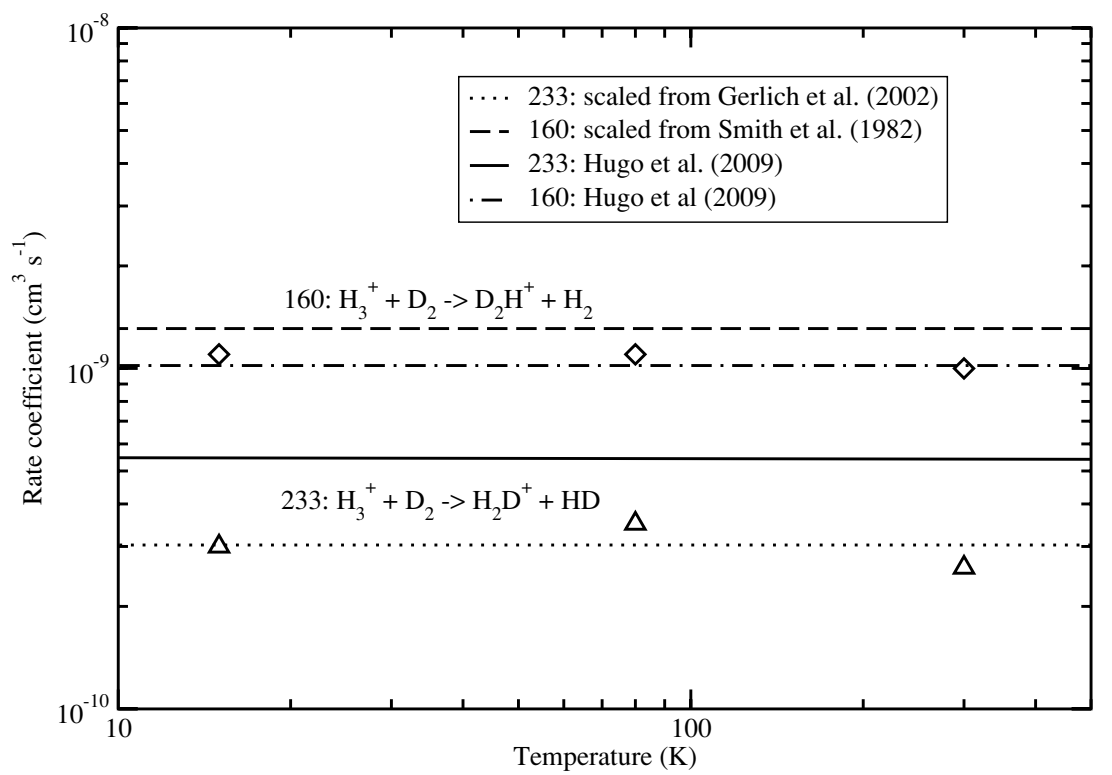

Figure 2. Comparison of rate coefficients for collisions of $\mathrm{H}_{3}^{+}$and $\mathrm{D}_{2}$ as indicated. Measurements of Gerlich et al. (2006): reaction 160 (diamonds), reaction 233 (triangles). See the text for other details.

estimated with simple mass scaling from similar reactions in Stancil et al. (1998), except as follows. Reactions 186, 229 (9), and 230 (14) are from Walmsley et al. (2004), reaction 231 (2) is from Shavitt (1959), and reaction 232 (4) is from Mielke et al. (2003). Reaction 252 is taken from Schulz \& Asundi (1967) and reactions 253-255 are found from reaction 252 through mass scaling. Reaction 44 is from Kreckel et al. (2010), while reactions $86,101,159,160,233-242,247$, and 248 are from Hugo et al. (2009). Reaction 256 describes photodetachment of $\mathrm{H}^{-}$due to distortion photons, and its rate was computed from the $\mathrm{H}$ recombination spectrum of Wong et al. (2006).

Figure 1 displays rate coefficients versus temperature for dissociative recombination reactions for $\mathrm{HD}_{2}^{+}$and $\mathrm{D}_{3}^{+}$. These figures compare rate coefficients mass-scaled from Wolf et al. (2006), theoretical rate coefficients from Kokoouline \& Greene (2005) for $\mathrm{HD}_{2}^{+}$and from Kokoouline \& Greene (2003) for $\mathrm{D}_{3}^{+}$, and rate coefficients measured by Mitchell et al. (1984). For reactions 209 (22), 210 (23), 211 (29), 212 (24), and 213 (30), we have opted to adopt the values of Mitchell et al. (1984), with branching ratios for $\mathrm{D}_{3}^{+}$from the $\mathrm{H}_{3}^{+}$analogues in McCall et al. (2004) and for $\mathrm{HD}_{2}^{+}$from the $\mathrm{H}_{2} \mathrm{D}^{+}$analogues in Larsson et al. (1996). Figure 1 lends confidence to the reactions in our network for which rate coefficients were found through simple mass scaling.

Figure 2 shows a comparison of rate coefficients for reactions 160 and 233 deduced from measurement, calculation, and mass scaling from the reaction

$$
\mathrm{H}_{3}^{+}+\mathrm{HD} \rightarrow \mathrm{H}_{2} \mathrm{D}^{+}+\mathrm{H}_{2} \text {. }
$$

We initially adopted the constant rate coefficient of $1.5 \times$ $10^{-9} \mathrm{~cm}^{3} \mathrm{~s}^{-1}$ measured by Smith et al. (1982). The resultant mass-scaled value (not shown) of reaction 233 obtained from reaction 38 is a factor of $\sim 3$ larger than the rate coefficient measured by Gerlich et al. (2006). However, Gerlich et al. 


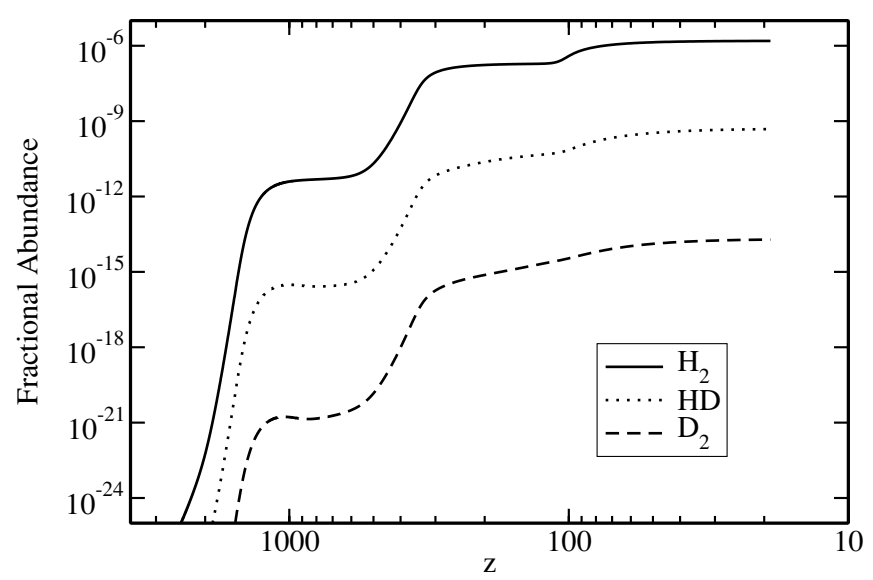

Figure 3. Fractional abundances as a function of redshift for $\mathrm{H}_{2}, \mathrm{HD}$, and $\mathrm{D}_{2}$.

(2002) measured the rate coefficient of reaction (38) at $10 \mathrm{~K}$ and obtained a significantly smaller value of $3.5 \times 10^{-10} \mathrm{~cm}^{3}$ $\mathrm{s}^{-1}$. Mass scaling this rate coefficient, we predict a value of $3.03 \times 10^{-10} \mathrm{~cm}^{3} \mathrm{~s}^{-1}$ for reaction 233 in excellent agreement with the Gerlich et al. (2006) measurements shown in Figure 2. For reaction 160, mass scaling the measurement of Smith et al. (1982) for reaction (38) results in close agreement to the measurements of Gerlich et al. (2006). Recently, Hugo et al. (2009) used a microcanonical model to estimate the rate coefficients for all isotopologues of reaction (38), but resolved according to nuclear spin statistics. Assuming statistical ortho and para populations, we deduced rate coefficients for reactions 160 and 233 shown in Figure 2. These rate coefficients are in excellent agreement with the experiment for reaction 160, but somewhat larger than that for reaction 233, again giving some confidence in the mass-scaling approach. However, we utilized the Hugo et al. (2009) rate coefficients for all isotopologues of reaction (38), but note that collisions with $\mathrm{H}$ and $\mathrm{D}$ dominate the chemistry. Finally, the endothermicities $\left(a_{3}\right)$ were adopted for reactions 72 and 100 from Gerlich et al. (2006). ${ }^{4}$

\section{RESULTS AND DISCUSSION}

Fractional abundances relative to hydrogen nuclei were calculated for all species in the full network. It was found that the new deuterium chemistry did not alter the fractional abundances of the previously computed species given in Stancil et al. (1998) and Lepp et al. (2002), except primarily as a result of updates to the cosmological constants. However, the rate coefficient for the associative attachment reaction 44 ,

$$
\mathrm{H}+\mathrm{H}^{-} \rightarrow \mathrm{H}_{2}+e^{-},
$$

was updated to the values obtained by Kreckel et al. (2010) and the contribution due to distortion photons on $\mathrm{H}^{-}$photodetachment was included following Switzer \& Hirata (2005) and Hirata \& Padmanabhan (2006). The net result being that the $\mathrm{H}_{2}$ fractional abundance was found to decrease at $z=20$ to $1.5 \times 10^{-6}$. This is somewhat larger than the values of $6 \times 10^{-7}$ and $3 \times 10^{-7}$ obtained by Hirata \& Padmanabhan (2006) and Vonlanthen et al. (2009), respectively. The difference is primarily due to the larger associative detachment rate of Kreckel et al. (2010) adopted here.

\footnotetext{
4 There is a misprint for the endothermicity for reaction 72 in Gerlich et al. (2006). The correct value is $a_{3}=458 \mathrm{~K}$ (D. Gerlich 2010, private communication).
}

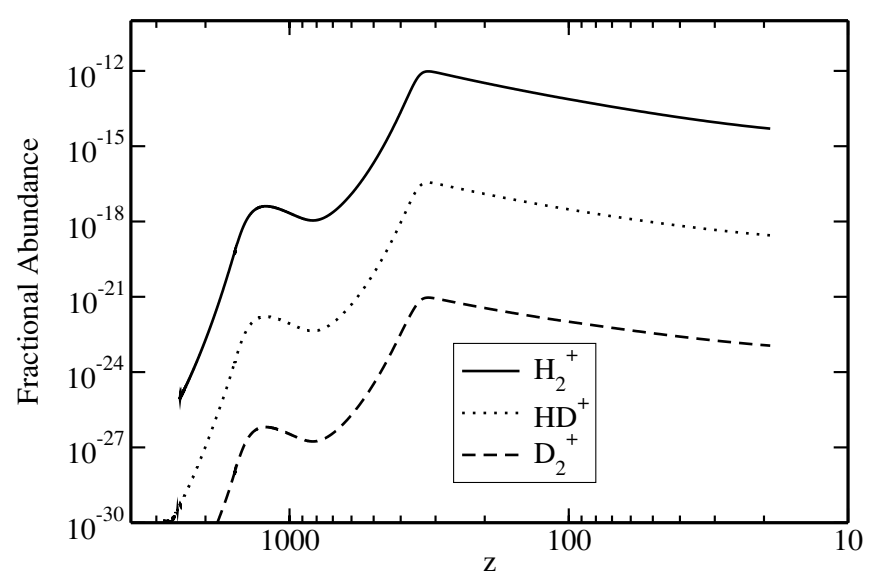

Figure 4. Fractional abundances as a function of redshift for $\mathrm{H}_{2}^{+}, \mathrm{HD}^{+}$, and $\mathrm{D}_{2}^{+}$.

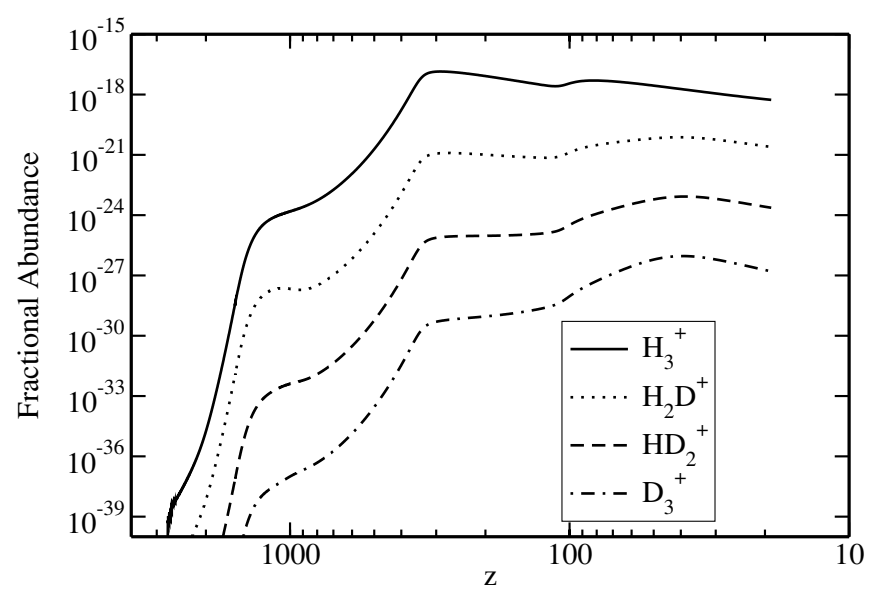

Figure 5. Fractional abundances as a function of redshift for $\mathrm{H}_{3}^{+}, \mathrm{H}_{2} \mathrm{D}^{+}, \mathrm{D}_{2} \mathrm{H}^{+}$, and $\mathrm{D}_{3}^{+}$.

The reduced abundance of $\mathrm{H}_{2}$ propagates through the network for those species whose primary formation processes depend on $\mathrm{H}_{2}$.

Figure 3 displays the fractional abundances as a function of redshift for $\mathrm{H}_{2}, \mathrm{HD}$, and $\mathrm{D}_{2}$. Figures 4 and 5 show the abundances for $\mathrm{H}_{2}^{+}, \mathrm{HD}^{+}$, and $\mathrm{D}_{2}^{+}$, and $\mathrm{H}_{3}^{+}, \mathrm{H}_{2} \mathrm{D}^{+}, \mathrm{D}_{2} \mathrm{H}^{+}$, and $\mathrm{D}_{3}^{+}$, respectively. For the most part abundances for isotopologues display similar behavior. This is partially due to the fact that many of our new reaction rate coefficients were scaled from similar reactions involving less deuterated species. As the molecules become more deuterated, the fractional abundances decrease at regular intervals in accordance with the primordial $\mathrm{D} / \mathrm{H}$ elemental abundance ratio.

One important trend to point out is that at lower $z$, the more deuterated a species, the greater the slope of the fractional abundance, except for the $\mathrm{H}_{2}^{+}$isotopologues. Figure 6 represents this trend in the isotopologues scaled by appropriate powers $m$ of the primordial $\mathrm{D} / \mathrm{H}$ ratio. This effect is a result of fractionation, which occurs because the more highly deuterated species are more deeply bound and thus have lower zero-point energies. Therefore, reactions tend to proceed in a direction that favors more highly deuterated species. The isotopologues of $\mathrm{H}_{2}^{+}$do not display much fractionation because they are formed primarily by radiative association. If no fractionation occurred, the abundance ratios in Figure 6 would approach one at low $z$. Roueff et al. (2007) considered this phenomenon for the cold interstellar medium, but where hydrogen is primarily in the 

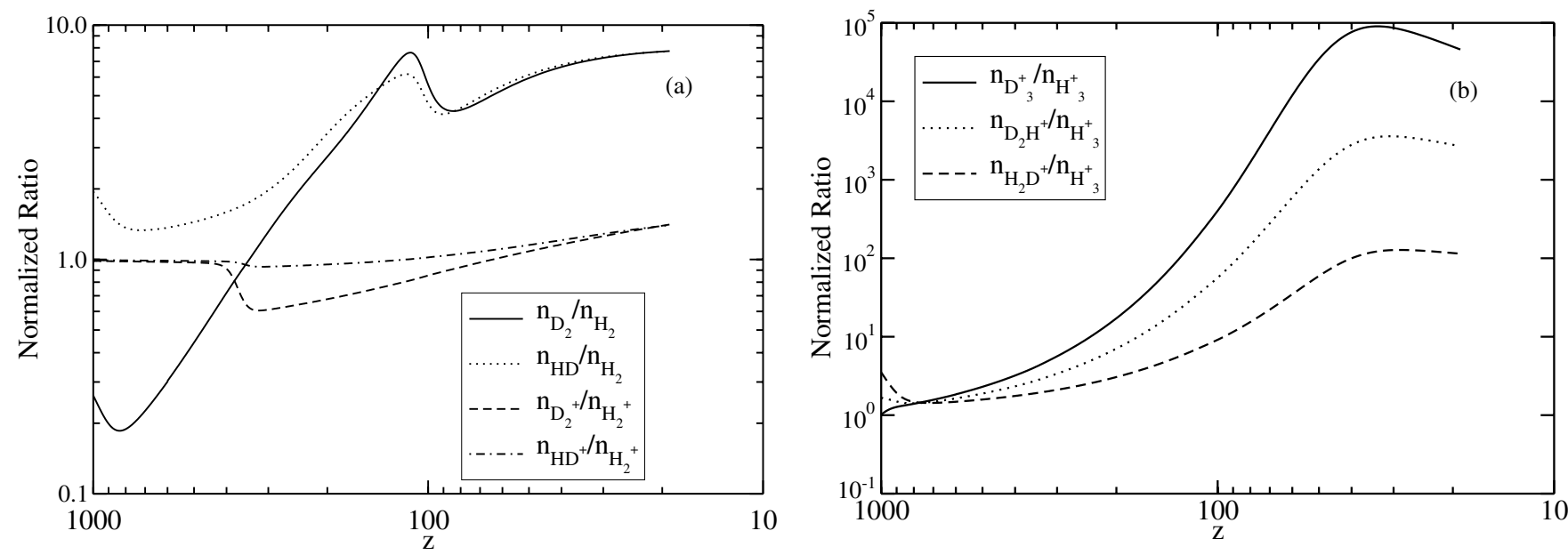

Figure 6. Fractionation in the isotopologues of (a) $\mathrm{H}_{2}, \mathrm{H}_{2}^{+}$and (b) $\mathrm{H}_{3}^{+}$, normalized by $[\mathrm{D} / \mathrm{H}]^{m}$, where $m$ is the number of $\mathrm{D}$ atoms in the molecule, i.e., $\left[f(x) / f\left(\mathrm{H}_{3}^{+}\right)\right] /[\mathrm{D} / \mathrm{H}]^{m}$.
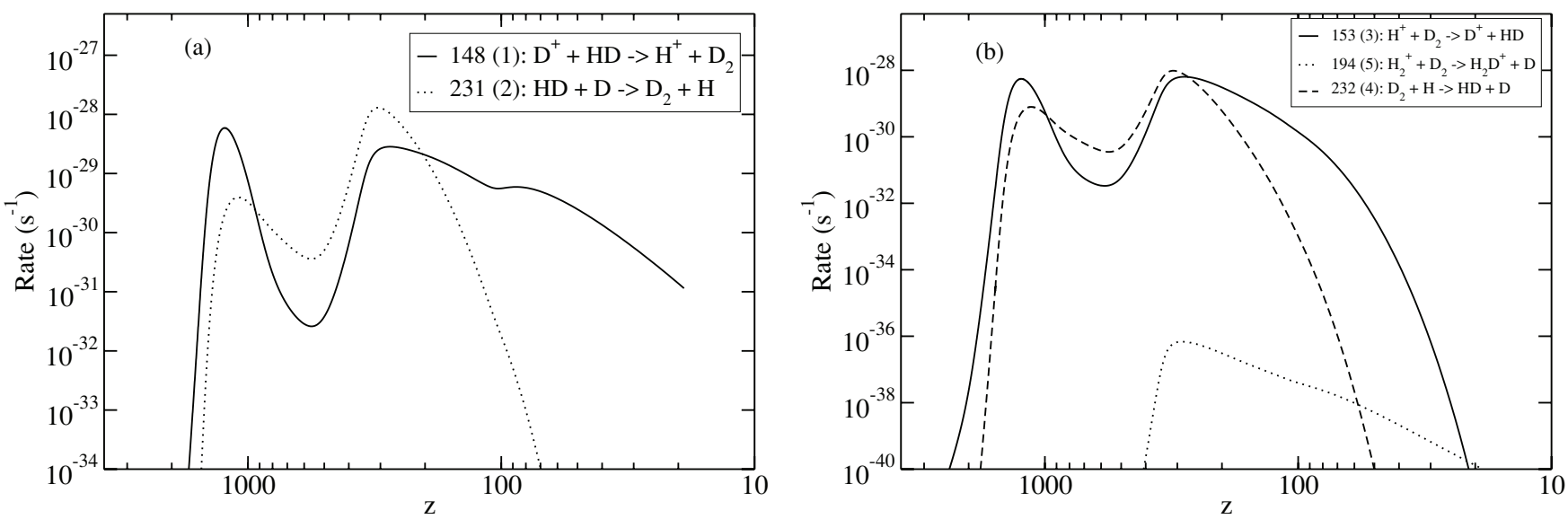

Figure 7. Rates of important reactions in the (a) creation and (b) destruction of $\mathrm{D}_{2}$.
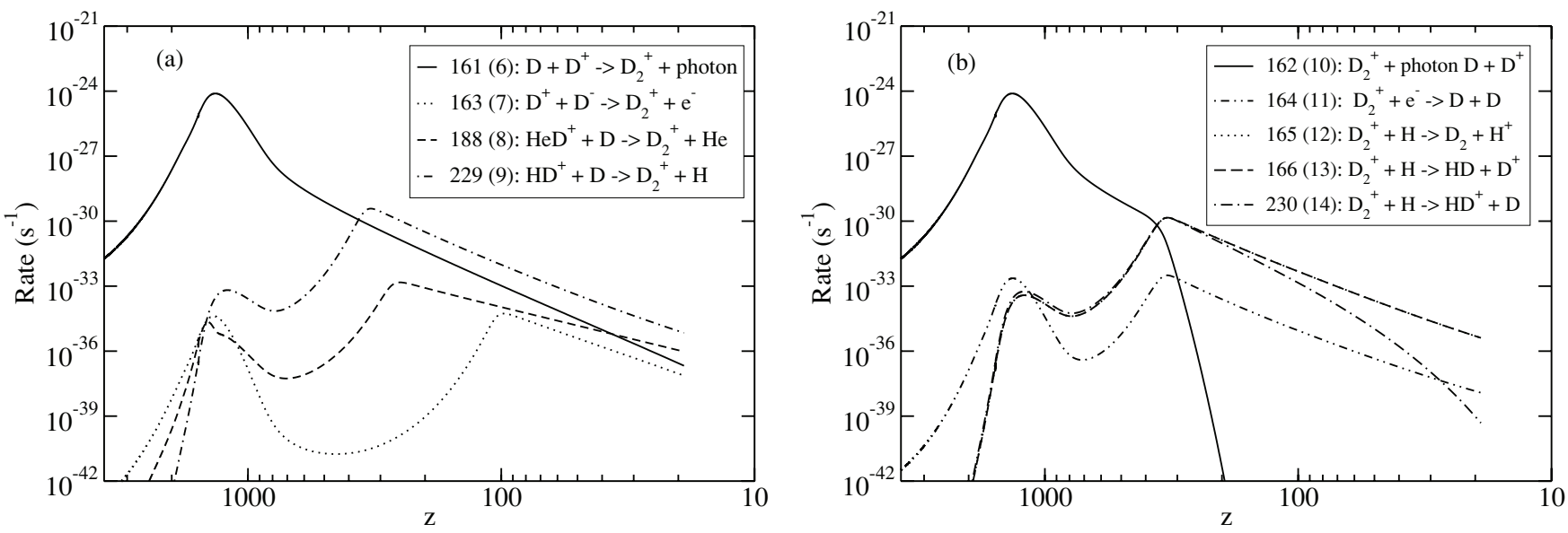

Figure 8. Rates of important reactions in the (a) creation and (b) destruction of $\mathrm{D}_{2}^{+}$.

form of $\mathrm{H}_{2}$, finding the fractionation ratios to scale as (HD/ $\left.\mathrm{H}_{2}\right)^{m}$, which is nearly $(2 \mathrm{D} / \mathrm{H})^{m}$.

Figures 7 through 10 display the rates for the creation and destruction reactions for $\mathrm{D}_{2}, \mathrm{D}_{2}^{+}, \mathrm{D}_{2} \mathrm{H}^{+}$, and $\mathrm{D}_{3}^{+}$. The dominant processes for the other isotopologues are given in Stancil et al. (1998). Note here that of the important reactions listed above, only reactions 148 (1), 153 (3), 209 (22), 210 (23), 211 (29), 212 (24), 213 (30), 229 (9), 230 (14), 231 (2), and 232 (4) have been obtained explicitly by either experiment or theory. The remaining rate coefficients have all been mass-scaled from similar reactions listed in Stancil et al. (1998) as we are aware of no other data. These rate coefficient estimates are the greatest sources of error in the current calculations.

There is generally a dearth of studies involving atomic hydrogen reactive collisions with molecular ions. This may be due to two issues: (1) the difficulty of producing a 

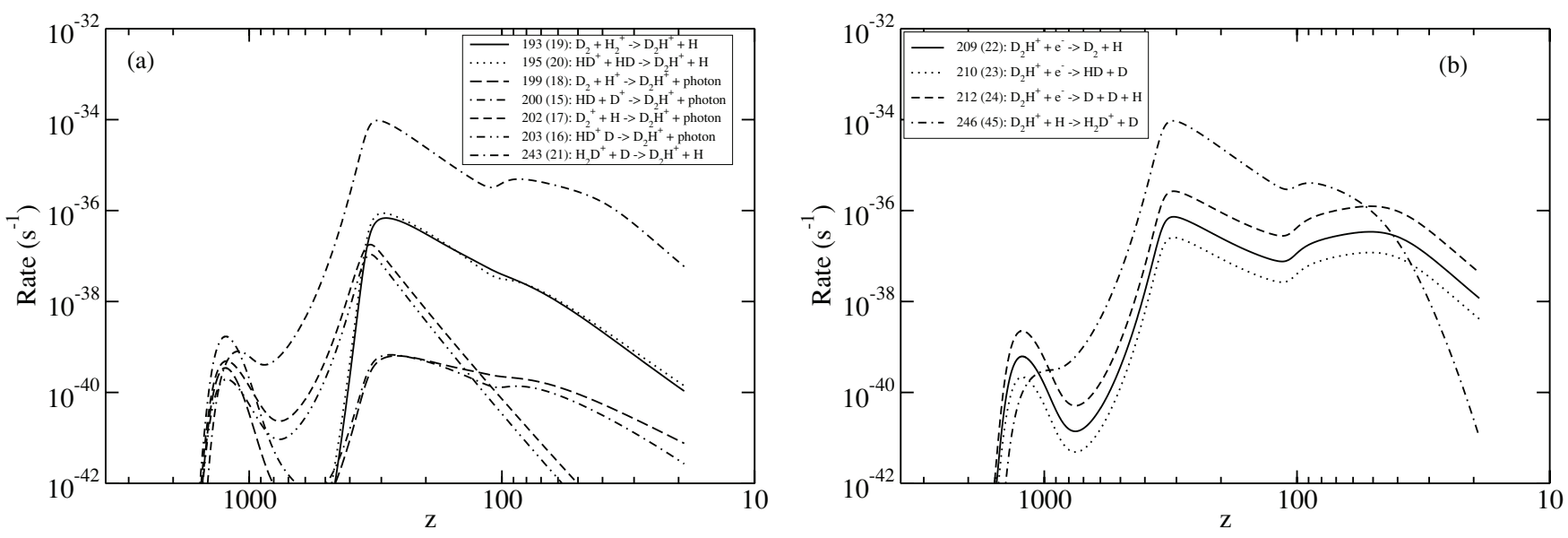

Figure 9. Rates of important reactions in the (a) creation and (b) destruction of $\mathrm{D}_{2} \mathrm{H}^{+}$.
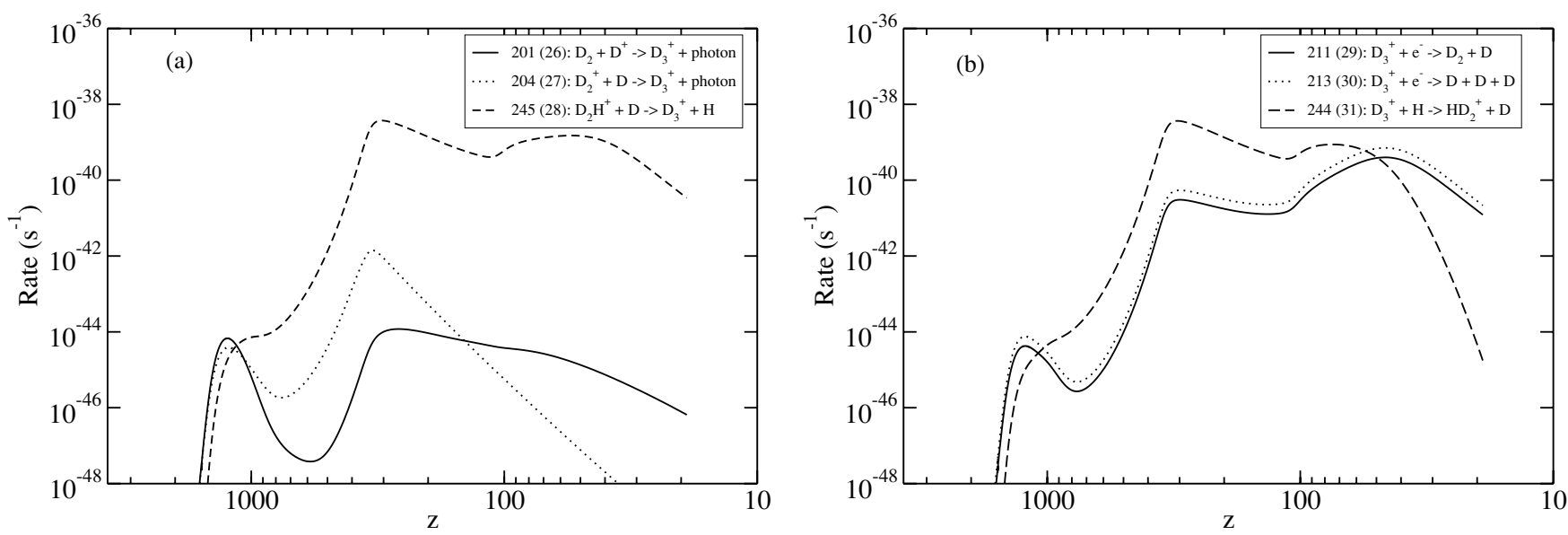

Figure 10. Rates of important reactions in the (a) creation and (b) destruction of $\mathrm{D}_{3}^{+}$.

low-energy atomic hydrogen beam and (2) that most reactive collision studies have considered molecular hydrogen (and its isotopologues) for applications to the interstellar medium. Further work on the reactive processes displayed in Figures 7 through 10 is needed in order to improve the abundance predictions of these highly deuterated species which may be possible with the development of Zeeman-decelerated atomic hydrogen beams (Hogan et al. 2008).

\section{CONCLUSION}

A chemical reaction network for the early universe has been improved and greatly expanded. Using the most accurate cosmological parameters, this network has been solved to obtain fractional abundances of all relevant primordial species, focusing on the highly deuterated species $\mathrm{D}_{2}^{+}, \mathrm{D}_{2}, \mathrm{D}_{2} \mathrm{H}^{+}$, and $\mathrm{D}_{3}^{+}$. Fractionation of isotopologues of $\mathrm{H}_{2}$ and $\mathrm{H}_{3}^{+}$is demonstrated. The accuracy of the predicted abundances could be greatly improved with the availability of measured or calculated rate coefficients for many deuterated reactions particularly those involving collisions of atomic $\mathrm{H}$ or $\mathrm{D}$ with hydrogen molecular ions.

We acknowledge support from NSF Grants AST-0607733 (C.D.G., P.C.S.), AST-0607524 (S.L.), and AST-0607532 (A.D.).

\section{REFERENCES}

Black, J. H. 1981, MNRAS, 197, 553

Burles, S., Nollett, K. M., \& Turner, M. S. 2001, ApJ, 552, L1

Galli, D., \& Palla, F. 1998, A\&A, 335, 403

Gerlich, D., Herbst, E., \& Roueff, E. 2002, Planet. Space Sci., 50, 1275

Gerlich, D., Windisch, F., Hlavenka, P., Plasil., R., \& Glosik, J. 2006, Phil. Trans. R. Soc., 364, 3007

Glover, S. C. O., \& Abel, T. 2008, MNRAS, 388, 1627

Hinshaw, G., et al. 2009, ApJS, 180, 225

Hirata, C. M., \& Padmanabhan, N. 2006, MNRAS, 372, 1175

Hogan, S. D., Wiederkehr, A. W., Andrist, M., Schmutz, H., \& Merkt, F. 2008, J. Phys. B: At. Mol. Opt. Phys., 41, 081005

Hugo, E., Asvany, O., \& Schlemmer, S. 2009, J. Chem. Phys., 130, 164302

Kokoouline, K., \& Greene, C. H. 2003, Phys. Rev. A, 68, 012703

Kokoouline, K., \& Greene, C. H. 2005, Phys. Rev. A, 72, 022712

Kreckel, H., Bruhns, H., Čížek, M., Glover, S. C. O., Miller, K. A., Urbain, X., \& Savin, D. W. 2010, Science, 329, 69

Larsson, M., et al. 1996, A\&A, 309, L1

Lepp, S., Stancil, P. C., \& Dalgarno, A. 2002, J. Phys. B: At. Mol. Opt. Phys., 35, R57

Linder, F., Janev, R. K., \& Botero, J. 1995, in Atomic and Molecular Processes in Fusion Edge Plasmas, ed. R. K. Janev (New York, NY: Plenum), 397

McCall, B. J., et al. 2004, Phys. Rev. A, 70, 052716

Mielke, S. L., Peterson, K. A., Schwenke, D. W., Garrett, B. C., Truhlar, D. G., Michael, J. V., Su, M. C., \& Sutherland, J. W. 2003, Phys. Rev. Lett., 91, 063201

Mitchell, J. B. A., Ng, C. T., Forand, J. L., Janssen, R., \& McGowan, J. Wm. 1984, J. Phys. B: At. Mol. Phys., 17, L909

Peebles, P. J. E. 1993, Principles of Physical Cosmology (Princeton, NJ: Princeton Univ. Press)

Porter, R. L., Ferland, G. J., MacAdam, K. B., \& Storey, P. J. 2009, MNRAS, 393, L36 
Roueff, E., Herbst, E., Lis, D. C., \& Phillips, T. G. 2007, ApJ, 661, L159

Schulz, G. J., \& Asundi, R. K. 1967, Phys. Rev., 158, 25

Shavitt, I. 1959, J. Chem. Phys., 31, 1359

Smith, D., Adams, N. G., \& Alge, E. 1982, ApJ, 263, 123

Stancil, P. C., Lepp, S., \& Dalgarno, A. 1998, ApJ, 509, 1

Switzer, E. C., \& Hirata, C. M. 2005, Phys. Rev. D, 752, 083002

Vastel, C., Phillips, T. G., \& Yoshida, H. 2004, ApJ, 606, L127
Vonlanthen, P., Rauscher, T., Winteler, C., Puy, D., Signore, M., \& Dubrovich, V. 2009, A\&A, 503, 47

Walmsley, C. M., Flower, D. R., \& Pineau des Forêts, G. 2004, A\&A, 418, 1035

Wang, J. G., \& Stancil, P. C. 2002, Phys. Scr. T, 96, 72

Wolf, A., et al. 2006, Phil. Trans. R. Soc. A, 364, 2981

Wong, W. Y., Seager, S., \& Scott, D. 2006, MNRAS, 367, 1666 